\title{
CAMBRIDGE
}

New and Exciting Titles in Psychology from

Cambridge University Press!

Are We Getting Smarter? Rising IQ in the Twenty-First Century James R. Flynn

\$65.00: Hb: 978-1-107-02809-8

\$22.00: Pb: 978-1-107-60917-4: 324 pp.

\section{Third Edition!}

Cognitive Behaviour

Therapy for Children and Families

Philip Graham and

Shirley Reynolds

Cambridge Child and Adolescent Psychiatry

\$85.00: Pb: 978-1-107-68985-5: 411 pp.

\section{Third Edition!}

Evolutionary Psychology

An Introduction

Lance Workman and

Will Reader

\$110.00: Hb: 978-1-107-04464-7

\$55.00: Pb: 978-1-107-62273-9: 550 pp.

Extraordinary Beliefs

A Historical Approach to a

Psychological Problem

Peter Lamont

\$85.00: Hb: 978-1-107-01933-1

\$29.99: Pb: 978-1-107-68802-5: 336 pp.

\section{Handbook of}

Implementation Science for Psychology in Education

Barbara Kelly and

Daniel F. Perkins

\$150.00: Hb: 978-0-521-19725-0: 500 pp.

Prices subject to change.

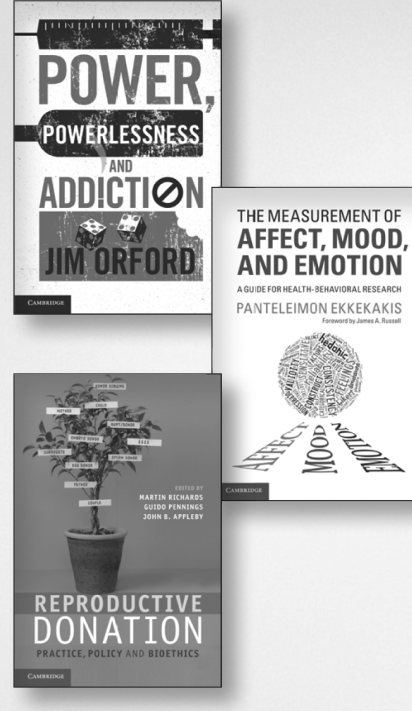

Power, Powerlessness and Addiction

Jim Orford

\$85.00: Hb: 978-1-107-03476-1

\$29.99: Pb: 978-1-107-61009-5: 270 pp.

Psychopathology

A Critical Perspective

Alison Lee and

Robert Irwin

\$120.00: Hb: 978-1-107-00981-3

\$50.00: Pb: 978-0-521-27902-4: 300 pp

Reproductive Donation

Practice, Policy and Bioethics

Martin Richards,

Guido Pennings and

John B. Appleby

\$99.00: Hb: 978-1-107-00777-2

\$34.99: Pb: 978-0-521-18993-4: 330 pp
Severe Domestic Squalor

John Snowdon,

Graeme Halliday and

Sube Banerjee

\$85.00: Hb: 978-1-107-01272-1: 223 pp.

The Cambridge Handbook of Human Affective Neuroscience

Jorge Armony and

Patrik Vuilleumier

\$140.00: Hb: 978-1-107-00111-4

\$60.00: Pb: 978-0-521-17155-7: 676 pp.

The Measurement of

Affect, Mood,

and Emotion

A Guide for Health-Behavioral Research

Panteleimon Ekkekakis and James A. Russell

\$95.00: Hb: 978-1-107-01100-7

\$32.99: Pb: 978-1-107-64820-3: 226 pp.

The Neuroscience of Freedom and Creativity Our Predictive Brain

Joaquín M. Fuster

\$80.00: Hb: 978-1-107-02775-6 \$27.99: Pb: 978-1-107-60862-7: 220 pp.

Understanding Autobiographical Memory

Theories and Approaches

Dorthe Berntsen and

David C. Rubin

\$99.00: Hb: 978-1-107-00730-7

\$38.99: Pb: 978-0-521-18933-0: 381 pp.

www.cambridge.org/psychology @CambUP_Psych 


\section{INSTRUCTIONS FOR CONTRIBUTORS}

\section{SUBMISSION OF MANUSCRIPTS}

Manuscripts should be submitted online via our manuscript submission and tracking site, http://www.editorialmanager.com/psm/. Full instructions for electronic submission are available directly from this site. To facilitate rapid reviewing, communications for peer review will be electronic and authors will need to supply a current e-mail address when registering to use the system.

Papers for publication from Europe (except those on genetic topics, irrespective of country), and all papers on imaging topics, should be submitted to the UK Office.

Papers from the Americas, Asia, Africa, Australasia and the Middle East (except those dealing with imaging topics), and all papers dealing with genetic topics, irrespective of country, should be sent to US Office.

Generally papers should not have text more than 4500 words in length (excluding these sections) and should not have more than a combined total of 5 tables and/or figures. Papers shorter than these limits are encouraged. For papers of unusual importance the editors may waive these requirements. A structured abstract of no more than 250 words should be given at the beginning of the article using the headings: Background; Methods; Results; Conclusions. The name of an author to whom correspondence should be sent must be indicated and a full postal address given in the footnote. Any acknowledgements should be placed at the end of the text (before the References section).

Declaration of Interest: A statement must be provided in the acknowledgements listing all financial support received for the work and, for all authors, any financial involvement (including employment, fees, share ownership) or affiliation with any organization whose financial interests may be affected by material in the manuscript, or which might potentially bias it. This applies to all papers including editorials and letters to the editor.

Contributors should also note the following:

1. S.I. units should be used throughout in text, figures and tables.

2. Authors should spell out in full any abbreviations used in their manuscripts.

3. Foreign quotations and phrases should be followed by a translation.

4. If necessary, guidelines for statistical presentation may be found in: Altman DG, Gore SM, Gardner MJ \& Pocock SJ (1983). Statistical guidelines for contributors to medical journals. British Medical Journal 286, 1489-1493.

REFERENCES (1) The Harvard (author-date) system should be used in the text and a complete list of References cited given at the end of the article. In a text citation of a work by more than two authors cite the first author's name followed by et al. (but the names of all of the authors should be given in the References section). Where several references are cited together they should be listed in rising date order. (2) The References section should be supplied in alphabetical order (authors' names in bold, journal titles in full), following the text. Some examples follow:

Miller PM, Byrne M, Hodges A, Lawrie SM, Johnstone EC (2002). Childhood behaviour, psychotic symptoms and psychosis onset in young people at high risk of schizophrenia: early findings from the Edinburgh high risk study. Psychological Medicine 32, $173-179$.

Cleckley HJ (1941). The Mask of Sanity, 2nd edn. Mosby: St. Louis, MO.

Brewer WJ, Wood SJ, DeLuca C, Pantelis C (2006). Models of olfaction for exploring neurodevelopment. In Olfaction and the Brain (ed. W. J. Brewer, D. Castle and C. Pantelis), pp. 97-121. Cambridge University Press: Cambridge.

(3) Online citations

doi (when published online prior to printed issue)

Lauritsen MB, Pedersen CB, Mortensen CB (2004). The incidence and prevalence of pervasive developmental disorders: a Danish population-based study. Psychological Medicine. Published online: 21 October 2004. doi:10.1017/ S0033291704002387.

URL

World Bank (2003). Quantitative techniques for health equity analysis - Technical Notes (http://siteresources.worldbank. org/INTPAH/ Resources/Publications/Quantitative-Techniques/health.eq tn07.pdf). Accessed 15 February 2006.

[Authors are requested to print-out and keep a copy of any online-only material, in case the URL changes or is no longer maintained.]

FIGURES AND TABLES Only essential figures and tables should be included. Further tables, figures, photographs and appendices, may be included with the online version on the journal website. To ensure that your figures are reproduced to the highest possible standards, Cambridge Journals recommends the following formats and resolutions for supplying electronic figures. Please ensure that your figures are saved at final publication size and are in our recommended file formats. Following these guidelines will result in high quality images being reproduced in both the print and the online versions of the journal. Line artwork: Format: tif or eps, Colour mode: black and white (also known as 1-bit), Resolution: 1200 dpi; Combination artwork (line/tone): Format: tif or eps, Colour mode: grayscale (also known as 8-bit), Resolution: $800 \mathrm{dpi}$; Black and white halftone artwork: Format: tif, Colour mode: grayscale (also known as 8-bit), Resolution: 300 dpi; Colour halftone artwork: Format: tif, Colour mode: CMYK colour, Resolution: 300 dpi. All photographs, graphs, and diagrams should be referred to as figures and should be numbered consecutively in Arabic numerals. Captions for figures should be typed double-spaced on separate sheets. Tables Tables should be numbered consecutively in the text in Arabic numerals and each typed on a separate sheet after the References section. Titles should be typed above the table.

PROOFS AND OFFPRINTS Page proofs will be sent to the author designated to receive correspondence. corrections other than to printer's errors may be charged to the author. The corresponding author of each paper will receive a PDF file of their article and hard copy offprints may be purchased if they are ordered on the form supplied when the proof is returned. 


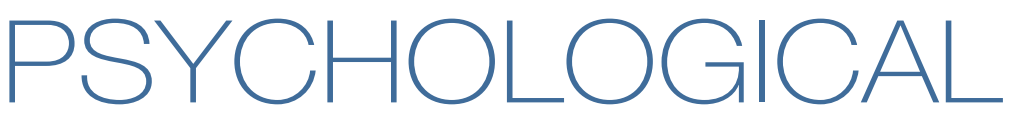

\section{CONTENTS}

\section{REVIEW ARTICLES}

Cognitive impairment in euthymic major depressive disorder: a meta-analysis

Bora E, Harrison BJ, Yücel M \& Pantelis C

Neurocognitive phenomics: examining the genetic basis of cognitive abilities

Donohoe G, Deary IJ, Glahn DC, Malhotra AK \& Burdick KE

\section{ORIGINAL ARTICLES}

Ageing and the prevalence and treatment of mental health problems

Jokela M, Batty GD \& Kivimäki M

Fronto-parietal white matter microstructural deficits are linked to performance IQ in a first-episode schizophrenia Han Chinese sample

Wang Q, Cheung C, Deng W, Li M, Huang C, Ma X, Wang Y, Jiang L, McAlonan G, Sham P, Collier DA, Gong Q,

Chua SE \& Li T

Degree of fetal growth restriction associated with schizophrenia risk in a national cohort

Eide MG, Moster D, Irgens LM, Reichborn-Kjennerud T,

Stoltenberg C, Skjærven R, Susser E \& Abel K

Hearing and speech impairment at age 4 and risk of later non-affective psychosis

Fors A, Abel KM, Wicks S, Magnusson C \& Dalman C

Specificity of childhood psychotic symptoms for predicting schizophrenia by 38 years of age: a birth cohort study

Fisher HL, Caspi A, Poulton R, Meier MH, Houts R,

Harrington $\mathrm{H}$, Arseneault $\mathrm{L}$ \& Moffitt TE

Tensor-based morphometry of cannabis use on brain structure in individuals at elevated genetic risk of schizophrenia

Welch KA, Moorhead TW, Mclntosh AM, Owens DGC, Johnstone EC \& Lawrie SM

Reflection impulsivity and response inhibition in first-episode psychosis: relationship to cannabis use Huddy VC, Clark L, Harrison I, Ron MA, Moutoussis M, Barnes TRE \& Joyce EM

Spiritual and religious beliefs as risk factors for the onset of major depression: an international cohort study

Leurent B, Nazareth I, Bellón-Saameño J, Geerlings M-I, Maaroos H, Saldivia S, Švab I, Torres-González F,

Xavier M \& King M

Screening medical patients for distress and depression: does measurement in the clinic prior to the consultation overestimate distress measured at home?

Hansen CH, Walker J, Thekkumpurath P, Kleiboer A, Beale C,

Sawhney A, Murray G \& Sharpe M
Differential patterns of activity and functional connectivity in emotion processing neural circuitry to angry and happy faces in adolescents with and without suicide attempt Pan LA, Hassel S, Segreti AM, Nau SA, Brent DA \& Phillips ML

Obese youths are not more likely to become depressed, but depressed youths are more likely to become obese Roberts RE \& Duong HT

Augmenting cognitive behaviour therapy for post-traumatic stress disorder with emotion tolerance training: a randomized controlled trial

Bryant RA, Mastrodomenico J, Hopwood S, Kenny L, Cahill C, Kandris E \& Taylor K

Genetic and environmental risk factors in males for self-report externalizing traits in mid-adolescence and criminal behavior through young adulthood Kendler KS, Patrick CJ, Larsson H, Gardner CO \& Lichtenstein P

A latent class analysis of drug abuse in a national Swedish sample

Kendler KS, Ohlsson H, Sundquist K \& Sundquist $J$

Validity of proposed DSM-5 diagnostic criteria for nicotine use disorder: results from 734 Israeli lifetime smokers Shmulewitz D, Wall MM, Aharonovich E, Spivak B, Weizman A Frisch A, Grant BF \& Hasin D

Embarrassment when illness strikes a close relative: a World Mental Health Survey Consortium Multi-Site Study Ahmedani BK, Kubiak SP, Kessler RC, de Graaf R, Alonso J, Bruffaerts R, Zarkov Z, Viana MC, Huang YQ, Hu C, Posada-Villa JA, Lepine JP, Angermeyer MC, de Girolamo G, Karam AN, Medina-Mora ME, Gureje O, Ferry F, Sagar R \& Anthony JC

Common mental disorder severity and its association with treatment contact and treatment intensity for mental health problems

ten Have M, Nuyen J, Beekman A \& de Graaf R

Sleep deprivation amplifies striatal activation to monetary reward

2097 Mullin BC, Phillips ML, Siegle GJ, Buysse DJ, Forbes EE \& Franzen PL

Recovery from chronic fatigue syndrome after treatments given in the PACE trial

White PD, Goldsmith K, Johnson AL, Chalder T \& Sharpe M; PACE Trial Management Group

Correspondence 